
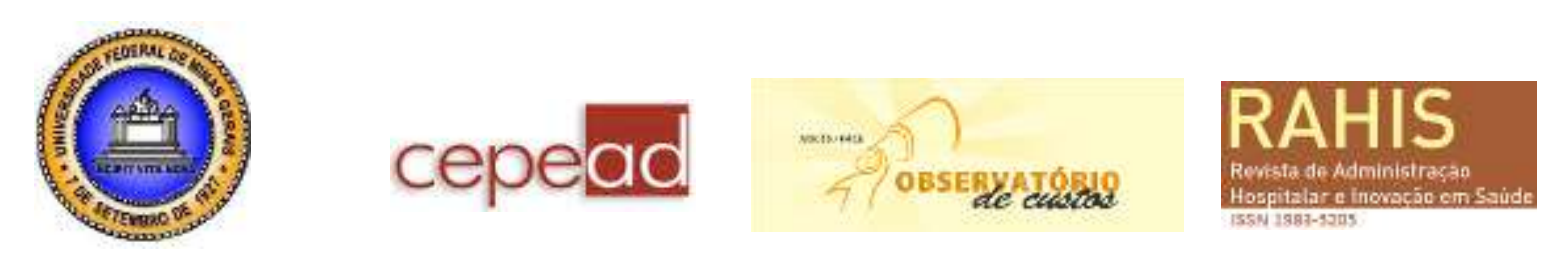

\title{
TRABALHO VOLUNTÁRIO E SEU GERENCIAMENTO: DESAFIOS PARA UM HOSPITAL COMUNITÁRIO ${ }^{1}$
}

\section{VOLUNTEER AND ITS MANAGEMENT: CHALLENGES FOR A COMMUNITY HOSPITAL}

\section{VOLUNTARIOS Y SU GESTIÓN: RETOS PARA UN HOSPITAL DE LA COMUNIDAD}

\author{
KLEBERSON MASSARO RODRIGUES \\ PUCPR \\ kleberson.massaro@grupomarista.org.br \\ VICTOR MEYER JUNIOR \\ PUCPR \\ victormeyerjr@gmail.com
}

\author{
JUNE ALISSON WESTARB CRUZ \\ PUCPR \\ june.cruz@pucpr.br
}

\section{RESUMO}

Embora a presença de voluntários em organizações hospitalares remonta a vários séculos o trabalho voluntário tem sido negligenciado por estudiosos das organizações e particularmente da administração de sistemas complexos como os hospitais. Mais recentemente, a gestão do trabalho voluntário tem se constituído em atividade relevante para a gestão hospitalar e começa a merecer maior atenção. $\mathrm{O}$ presente estudo tem como objetivo examinar as práticas de gestão do trabalho voluntário desenvolvido em um hospital comunitário brasileiro. Trata-se de um estudo de caso, de caráter descritivo, em que são examinadas as práticas gerenciais desenvolvidas com o trabalho voluntário analisando sua relevância, bem como os desafios encontrados em sua gestão em um Hospital Comunitário. Os dados foram coletados por meio de entrevistas semi estruturadas com gestores e voluntários, além da análise documental e observação não participante. A análise revelou que o trabalho voluntário caracteriza-se por contribuir, efetivamente, para a humanização, maior integração dos setores, e utilização de recursos internos, e melhoria da gestão do próprio hospital além de reforçar a imagem social e legitimidade institucional. Observou-se que a gestão do trabalho voluntário enfrenta desafios relacionados à escassez de recursos e falta de maior profissionalização da gestão do trabalho voluntário. As conclusões apontam para a necessidade de maior e melhor qualificação da gestão do voluntariado com impacto positivo na melhoria da qualidade dos serviços hospitalares e do desempenho organizacional.

PALAVRAS-CHAVE: Hospital Comunitário, Gestão, Trabalho Voluntariado.

\footnotetext{
${ }^{1}$ Submetido em 30 de Outubro 2013. Aceito em 02 de abril de 2014. O artigo foi avaliado segundo o processo de duplo anonimato e avaliado pelo editor. Editores responsáveis: Márcio Augusto Gonçalves e Lucas Maia dos Santos. Reprodução parcial ou total e trabalhos derivativos permitidos com a citação apropriada da fonte.
} 

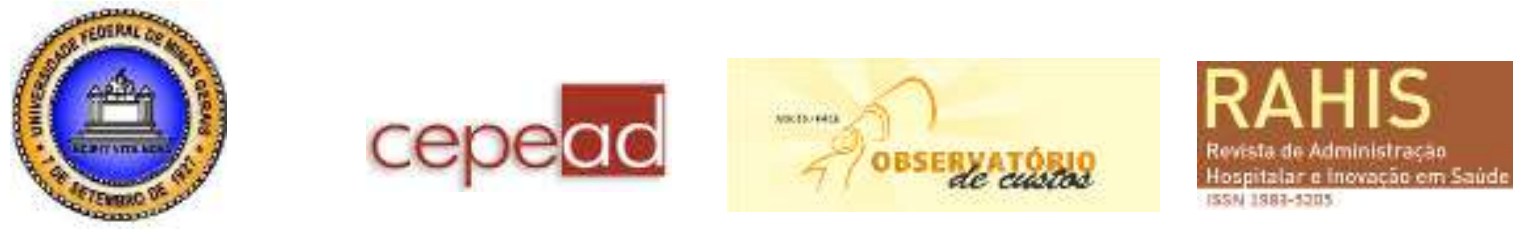

\begin{abstract}
Although the presence of volunteers in hospital organizations dates back many centuries, volunteer work has been neglected by organizational researchers, particularly by those of management of complex systems like hospitals. Management of volunteer work has recently become an important activity for hospital management and begins to receive a greater attention. This study aims to examine management practices of volunteer work developed in a Brazilian community hospital. It is a descriptive case study which examines management practices developed for volunteer work focusing on the analysis of its relevance, as well as the challenges encountered in its management in a community hospital. Data were gathered through semi-structured interviews with managers and volunteers, besides document analysis, and non-participant observation. The analysis revealed that volunteer work effectively contributes to humanization, greater integration of departments, and use of internal resources, as well as improvement of hospital management, and reinforcement of its image and institutional legitimacy. It was observed that volunteer work management faces challenges related to resource shortage and lack of professionalization of its management. Conclusions point out to the need of higher and better qualification of volunteer work management with a positive impact on the improvement of hospital service quality and of organizational performance.
\end{abstract}

KEY WORDS: Community Hospital, Management, Volunteer Work.

\title{
RESUMEN
}

Aunque la presencia de voluntarios en las organizaciones hospitalarias se remonta a varios siglos el voluntariado ha sido descuidado por los estudiosos de las organizaciones y en particular la gestión de los sistemas complejos, como los hospitales. Más recientemente, la gestión del voluntariado se ha constituido como relevante para la actividad de gestión de los hospitales y comienza a recibir mayor atención. Este estudio tiene como objetivo examinar las prácticas de gestión de trabajo voluntario en un hospital de la comunidad brasileña. Este es un caso de estudio, de carácter descriptivo, se examinan las prácticas de gestión desarrolladas con el trabajo voluntario de analizar su pertinencia, así como los desafíos que enfrentan en su gestión en un hospital de la comunidad. Los datos fueron recolectados a través de entrevistas estructuradas con gerentes y voluntarios entrevistas semi, además de documentar el análisis y la observación no participante. El análisis mostró que el trabajo voluntario se caracteriza por contribuir de manera efectiva a la humanización, una mayor integración de los sectores, y el uso de los recursos internos, y la mejora de la gestión del hospital, así como el fortalecimiento de la imagen social y la legitimidad institucional. Se observó que la gestión del voluntariado se enfrenta a los desafíos relacionados con la escasez de recursos y la falta de una gestión más profesional de trabajo voluntario. Los resultados apuntan a la necesidad de una mayor y mejor cualificación de la gestión del voluntariado, con un impacto positivo en la mejora de la calidad de los servicios hospitalarios y el desempeño organizacional.

PALABRAS CLAVE: Hospital Comunitario, Administración, Trabajo Voluntario 


\section{INTRODUÇÃO}

Uma das principais características das organizações do terceiro setor é a relevância social de seus serviços. Assim, estas organizações caracterizam-se por sua missão e pelo valor social agregado. Nos últimos anos as organizações sem fins lucrativos - ONGS têm apresentado expressivo crescimento, ocupando espaços em aberto negligenciados pelo Estado e de pouco ou nenhum interesses de parte das empresas. Para Drucker (2005) as ONGS existem, essencialmente, para promoverem mudanças nos indivíduos e, por via de conseqüência, na própria sociedade.

As Organizações Sem Fins Lucrativos (ONGS), inseridas no terceiro setor, dependem de apoio substancial da própria sociedade para poderem bem desempenhar suas atividades. Nesse contexto, o trabalho voluntário se insere como uma atividade fundamental na organicidade, vitalidade, sistematização e estrutura destas organizações, em especial, em organizações hospitalares. Como bem destaca Drucker (2005) uma das características marcantes das organizações sem fins lucrativos é o trabalho voluntário ou não remunerado.

Para Meyer Jr.et al. (2012) este tipo de trabalho contribui, primeiramente, para a assistência e cuidado direto aos pacientes. Em segundo lugar, na captação de recursos por meio de estratégias variadas, marketing e relacionamento com pessoas da sociedade civil e, finalmente em terceiro lugar, contribuem para a redução de custos operacionais ao executarem tarefas que seriam feitas profissionais contratados.

Como destacam Meyer Jr., Pascucci and Murphy (2012) os voluntários, devidamente gerenciados, podem contribuir para a melhoria dos serviços hospitalares e para o cumprimento da missão social. No entendimento de Moore (2000) a importância do trabalho voluntário está relacionada ao apoio à capacidade operacional e legitimidade dada à organização, agregando valor social.

Percebe-se, que os voluntários, quando bem geridos, podem contribuir, de forma significativa, para o cumprimento de diversas atividades bem como para o desempenho organizacional, com destaque para a própria humanização, como nas organizações hospitalares. Neste contexto os voluntários, como colaboradores, podem contribuir para a promoção da qualidade dos serviços prestados com benefícios claros para os usuários destes serviços criando um clima que propicie boa acolhida, boa ambiência e bom tratamento. Os voluntários, potencialmente poderão contribuir não só para a melhoria dos serviços de saúde mas também na minimizando gastos operacionais e fortalecendo a imagem organizacional ao atuarem como propagadores dos bons serviços prestados junto a sociedade.

Nesse sentido, o objetivo deste trabalho é examinar as práticas de gestão do voluntariado, em particular as atividades de atrair, organizar, liderar e avaliar o trabalho voluntário de um hospital comunitário, brasileiro. Tal proposição se justifica pela importância dos benefícios gerados por este tipo de trabalho e de seu impacto no desempenho de uma organização hospitalar em especial na melhoria dos serviços de saúde prestados à comunidade. 

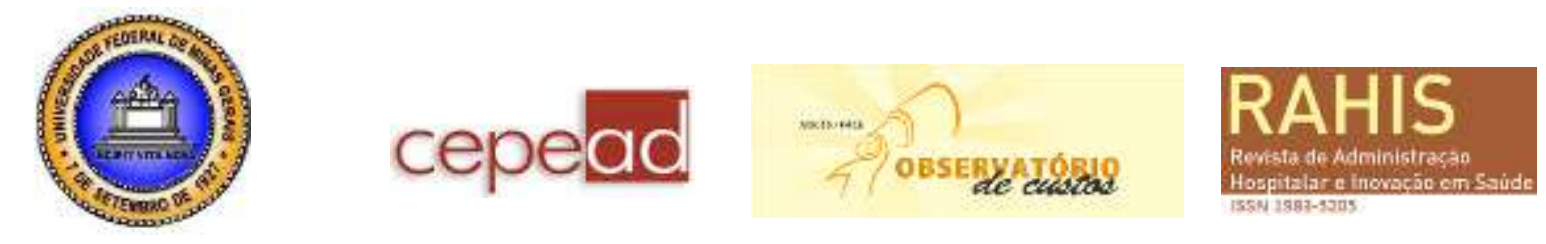

\section{AS ONGS E SUA GESTÃO}

Para Oster (1995), as ONGS se diferenciam de organizações públicas e privadas em razão da natureza social da sua finalidade e destacam-se pela diversidade de bens e serviços, a força de trabalho, bem como por seus recursos e receitas. A diversidade de bens e serviços se justifica devido à necessidade das ONGS obterem a captação de recursos, principalmente, financeiros. A força de trabalho pode ser proveniente tanto de profissionais remunerados como de voluntários, motivados por fatores diversos, desempenham várias atividades neste tipo de organização. Os recursos e receitas financeiras podem ser provenientes tanto da venda de múltiplos serviços, quanto da captação de doações provenientes de outras organizações e da própria sociedade civil.

As ONGS apresentam características próprias que necessitam ser consideradas na gestão deste tipo de organização. Para Moore (2000), a visão da gestão das ONGS é associada a sua missão e as atividades particulares que empreende para atingi-la. Bryson (2004) por sua vez destaca que a dificuldade em se gerenciar ONGS reside justamente no fato destas organizações não terem fins lucrativos, mas sim cunho social explicitados em sua missão.

Ainda quanto às características distintivas das ONGS Drucker (1997) reforça o entendimento de que estas organizações têm como "produto final", um paciente curado, uma criança que aprende, um jovem que se transforma em um adulto com autorrespeito, ou seja, um ser humano mudado. Como destaca o autor:

A instituição sem fins lucrativos não está meramente prestando um serviço. Ela não quer que o usuário final seja um usuário, mas sim um executor. Ela utiliza um serviço para provocar mudanças em um ser humano (...). Ela cria hábitos, visão, compromisso, conhecimento. Ela procura tornar-se parte do receptor, ao invés de uma mera fornecedora. Até que isso aconteça, a instituição sem fins lucrativos não teve resultados; ela teve somente boas intenções (DRUCKER, 1997, p. 40).

Um dos desafios das ONGS tem sido a inexistência de abordagens próprias de gestão e da diversidade de tipos e atividades desenvolvidas por estas organizações. Moore (2000) destaca que a gestão de organizações do terceiro setor deve levar em conta dois aspectos de importância crucial: o valor produzido encontra-se na realização dos fins sociais e não na geração de receitas e o fato de que suas receitas se originarem principalmente de outras fontes que não a venda de produtos para seus usuários.

Neste aspecto, Soares e Melo (2009) corroboram afirmando que é necessário configurar as práticas gerenciais de organizações do Terceiro Setor como uma prática social, pois isso proporcionará uma melhor compreensão tanto dos processos e estruturas dessas organizações quanto das transformações e da sua própria profissionalização.

Sendo assim deve-se dar atenção às particularidades identitárias que visam potencializar a legitimidade social das ONGS. Esse reconhecimento é fundamental para que se forme um círculo virtuoso na percepção da comunidade em seu entorno, destaca Moore (2000). A legitimidade, mais do que a eficácia e eficiência deve ser de grande preocupação das organizações sem fins lucrativos, pois como afirma Dart (2004), legitimidade moral é a espécie de legitimidade com maior relevância para explicações de organizações sociais.

Ao examinar o papel das lideranças Dart (2004) destaca que os empreendedores sociais desempenham o papel de agentes de mudança no setor social, por: 1. Adotar uma missão para criar 

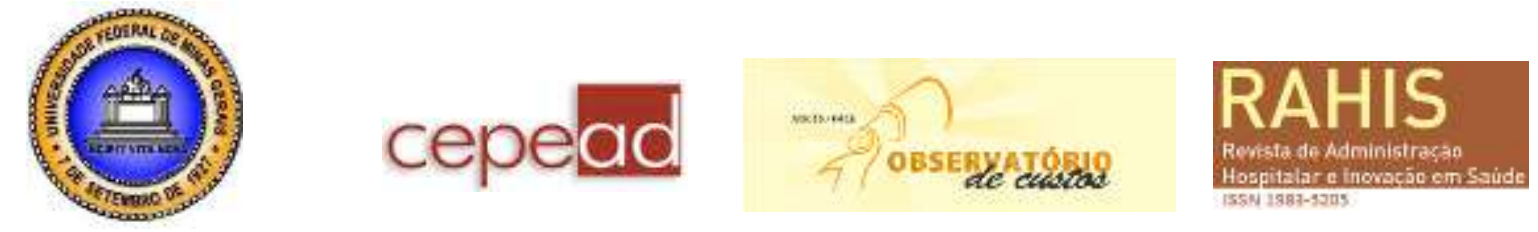

e manter valor social; 2. Reconhecer e buscar implacavelmente novas oportunidades para servir a essa missão; 3. Engajar-se em um processo de contínua inovação, adaptação e aprendizagem; 4. Agir com ousadia sem estar limitado pelos recursos atualmente em mãos; e, finalmente, 5. Exibir um elevado senso de responsabilidade para com os eleitores servidos e para os resultados criados. Contudo os líderes devem abdicar de seus interesses pessoais para que as organizações sem fins lucrativos sobrevivam sadiamente, evidencia Bryson (2004).

Ainda, segundo Bryson (2004), as tarefas gerenciais realizadas no desenvolvimento da estratégia têm a finalidade de garantir a qualidade, reforçar o desempenho, apoiar as mudanças tecnológicas e administrativas, obter feedback sobre a eficácia das estratégias praticadas e, em especial de sua capacidade de resposta às mudanças impostas às organizações sem fins lucrativos por um ambiente dinâmico e em constante mudança.

Para Oster (1995) a natureza e intensidade do trabalho das organizações sem fins lucrativos e força tanto a importância da gestão de recursos humanos quanto a contribuição de força de trabalho voluntário que somado a elevada concentração de profissionais, como agentes autônomos, fazem a questão de motivação, integração e controle do trabalho destes grupos algo que contribui para elevar a complexidade organizacional. Neste sentido, Ridder, Piening and Baluch (2012), afirmam que as arquiteturas da gestão de recursos humanos têm sido negligenciadas embora sejam vitais para o equacionamento dos problemas internos e externos deste tipo de organização.

É necessário observar que na gestão destas organizações estão envolvidas muitas variáveis que devem ser consideradas pelos gestores e que, também estão relacionadas com o processo de formação das estratégias. Meyer, Pascucci e Mangolim (2012, p. 52) afirmam que:

[...] por envolver aspectos racionais, emocionais, intuitivos, simbolismos e manobras políticas, não se constitui em atividade simples para os gestores. A materialização de estratégias requer dos gestores uma combinação de conhecimento, experiência, criatividade, sensibilidade, insights, arte e negociação, entre outras habilidades, certamente, mais exigidas e necessárias na gestão de sistemas organizacionais complexos.

Contudo a gestão de ONGS é altamente desafiadora necessitando de pesquisa, reflexões e mudanças contínuas tanto para contribuir eficazmente para com os processos organizacionais, quanto para responder aos desafios de torna-la aderente aos propósitos e identidade das organizações inseridas neste setor.

\section{O TRABALHO VOLUNTÁRIO E SUA RELEVÂNCIA}

Na última década tem havido um aumento significativo no número de empresas, organizações e pessoas que têm buscado aderir ao voluntariado (PINTO, GUEDES e BARROS, 2006). O fato parece coincidir com a promulgação do Ano Internacional do Voluntariado, em 2001, pela ONU.

O voluntariado não é um fenômeno recente. Essa prática foi recorrente em quase todas as sociedades e culturas, estando basicamente relacionada ao cuidado dos socialmente vulneráveis: dos enfermos, dos deficientes, dos indigentes, dos idosos, das viúvas e crianças órfãs. Kisnerman (1983) ressalva que, na história remota da sociedade ocidental, as "obras de bondade e caridade" realizadas por uma pessoa durante toda a vida equivaliam ao exercício moral mais importante para tornar-se um bom cristão. 

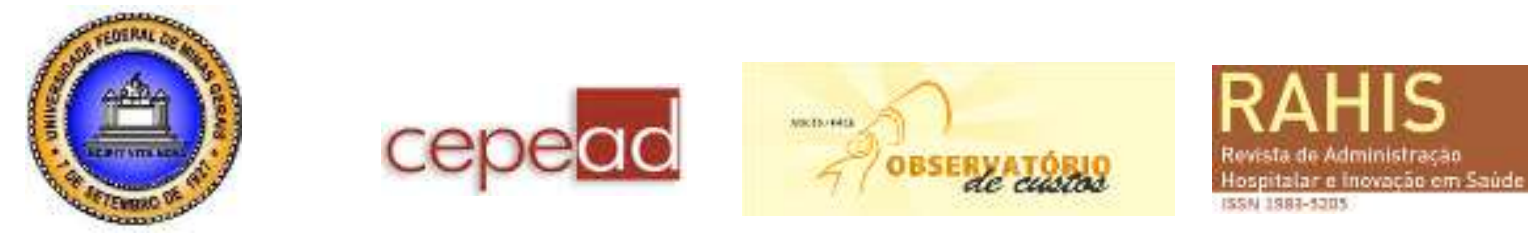

O Programa de Voluntários das Nações Unidas (UNV) conceitua o "voluntário" com sendo a pessoa que dedica algum tempo sem remuneração alguma a atividades ou trabalhos, organizados ou não, em âmbito local ou internacional, que promovam o bem-estar social e os direitos humanos. Essa pessoa valoriza o livre arbítrio, o compromisso, o engajamento e a solidariedade, que são as bases do voluntariado. Para Kohan (1965), o trabalho voluntário, ou voluntariado, pode ser definido como o esforço oferecido espontaneamente, sem remuneração, por qualquer pessoa que deseje colaborar em organismos que trabalham em favor do bem-estar da comunidade.

Para Domeneghetti (2001) o voluntariado é uma ferramenta estratégica na formação e ampliação do capital social. Ainda na perspectiva de contribuição social Anheier e Salamon (1999), destacam que diversas instituiçõesinternacionais identificam forte ligação entrea participação individualna vida pública,voluntariadoe da democracia.Para estes autores o voluntariado funciona como uma cola social, pois mantém sociedades modernas juntas, destacando a cidadania como uma relevante perspectiva na sociedade.

No contexto de atuação do terceiro setor, Hudson (1999, p. 11) enumera três contribuições importantes do voluntariado para a sociedade: a) representação: a ação voluntária não é mero provedor de serviços sociais ao lado do Estado, mas, num estado democrático, é aquilo que contribui para o processo representativo, para a integração social e para o fomento da política pública; b) inovação: os corpos de voluntariados têm se demonstrado uma fonte importante de inovação, uma vez que as soluções são desenvolvidas por aqueles que estão diretamente envolvidos com o problema e c) cidadania: em sua natureza subjetiva, os voluntários trabalham engajados na solução de diversos problemas e na melhoria da vida em comum.

Como destacam Meyer Jr., Pascucci e Murphy (2010)o voluntariado no meio hospitalar traz benefícios, tais como: a) aos pacientes atendidos, pois os dá conforto psicológico e físico durante a internação; b) à imagem ao próprio hospital, pois como agente estratégico pode promover a legitimidade social; c)à gestão do hospital com informações relevantes sobre ambiente, clima, relacionamentos e postura comportamental dos colaboradores da organização em que atua; d) à contribuição econômica tanto com doações financeiras, quanto com doações de seus serviços sem nenhum tipo de remuneração.

Contudo, o trabalho voluntário não pode ser gerido de acordo com as mesmas políticas de gestão das pessoas que são pagas para desenvolver atividades profissionais. Este aspecto constituise em um dos grandes desafios para os gestores de ONGS ao procurar integrar, lado a lado, colaboradores voluntários e profissionais remunerados do terceiro setor.

\section{A GESTÃO DO TRABALHO VOLUNTÁRIO EM HOSPITAIS}

Os hospitais podem ser identificados como sistemas complexos. A teoria dos sistemas adaptativos complexos, segundo Stacey, (1996), destaca que a organização é um todo que emerge em decorrência das intensas interações entre indivíduos que os integram chamados agentes que possuem autonomia no desempenho de suas ações. Estas organizações, segundo a mesma teoria, estão em contínua transformação sendo que as organizações mantém uma dinâmica relação com o ambiente, daí decorrendo uma co-evolução. Como consequência disso tem-se um sistema complexo cujo comportamento é paradoxal, dinâmico e imprevisível. Para que as organizações 

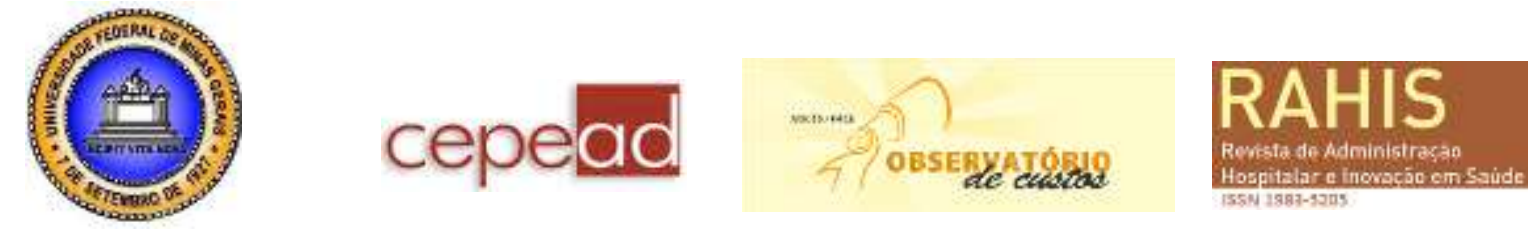

possam sobreviver necessitam inovar e esta se constitui em condição para agir diante dos desafios impostos pelas forças ambientais (STACEY, 1996, 2000).

Assim, a gestão de sistemas complexos implica em saber conviver com a incerteza e a imprevisibilidade. Certamente isto é verdadeiro para todas as organizações e, particularmente, para organizações complexas como as organizações hospitalares. Estas são identificadas como pluralistas, ambíguas e profissionais apresentando implicações em sua forma de gestão e funcionamento (Meyer Jr. Pascucci e Murphy, 2012).

Como ressaltam Pascucci e Meyer Jr. (2011, p. 4), "Em organizações complexas, os objetivos são difusos, ambíguos e pouco consensuais. A imprevisibilidade, a incerteza, a característica não linear das atividades e a variedade de atores contribuem para a ambiguidade e dificuldade de consenso, encontradas em organizações complexas". Como consequência a gestão deste tipo de organização considera em suas abordagens variáveis distintas daquelas presentes em organizações tipo "máquina" a que se refere Mintzberg (1994) em seu processo gerencial de forma a fazer face a dinamicidade interna e aos desafios ambientais.

Os hospitais, no entendimento de Meyer Jr., Pascucci e Murphy (2010) são igualmente caracterizados por serem organizações profissionais permeadas por especialidades diversas, necessidades emergenciais, demandas sempre novas e incertas e, como resultado, marcadas pela interdependência entre setores, profissionais e sua missão social. Trata-se de ambientes que reúnem a necessidade da precisão tecnológica, da boa gestão, de eficiência profissional associadas à humanidade, aos valores sociais, à promoção da vida em sua dimensão integral.

Nesse contexto hospitalar é que se deve pensar a existência do serviço voluntário. Para Oster (1995), em organizações dessa natureza, "a presença de voluntários fora da hierarquia pode provocar profundos efeitos". Como apontam Meyer Jr., Pascucci e Murphy (2010), em meio às atividades hospitalares, os voluntários podem: ser fonte de assistência social e psicológica aos pacientes e seus familiares; contribuir de forma não dependente da estrutura formal para a formulação de estratégias; constituírem-se em grandes elos entre a organização e a sociedade e contribuir como agentes de captação de recursos e fortalecimento da imagem organizacional. Quando bem gerenciados podem até mesmo contribuir mais significativamente com serviços mais estreitamente ligados aos processos de tratamento clínico (Meyer Jr., Pascucci e Murphy (2010).Além disso podem desenvolver atividades em áreas como: atendimento ao público, atendimento telefônico, leitura de livros a pacientes, visitas solidárias, conversa com familiares de pacientes, dentre outras variando de acordo com as demandas e necessidades da organização hospitalar onde se insere.

O trabalho voluntário transcende o exercício humano da caridade e do bem estar, haja vista ser possível integrar mediante uma gestão adequada, o trabalho voluntário com o trabalho profissional remunerado presente em organizações como os hospitais. A este respeito Meyer, Pascucci e Murphy (2010, p. 3) afirmam:

A relevânciae credibilidade do trabalho voluntário vai muito além do apoio social e psicológico nas questões organizacionais. Uma análise econômica por Handye Srinivasan (2005), considerando a demanda por voluntários em hospitais canadenses mostraque fatores como a produtividade, a produção e mão de obra influenciama demanda portrabalho voluntário. Ao estudaro impacto e profissionalismo que os voluntários têm no desempenho do hospital, Hotchkiss, Fottlere Unruh (2009) encontraram significativa redução de custos e aumento 

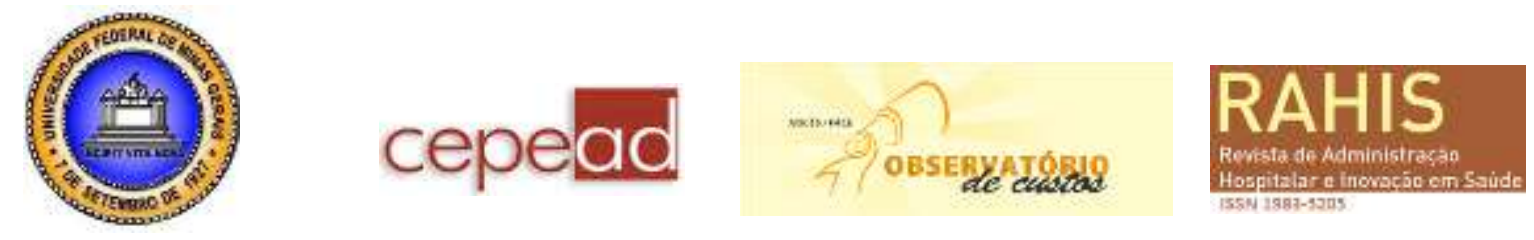

dasatisfação do paciente. Outros estudos semelhantes abordaram a equivalência dos funcionários remunerados e voluntários e as grandes expectativas dos hospitais vis-à-vis as limitações de voluntários baseado no curto espaço de tempo e escassez de informações disponíveis (Handy, Mook \& Quarter, 2008). Programas de voluntariado bem desenvolvidos em hospitais na Austrália (Prabhu, Hanley \& Kearney, 2008) forneceram mais de 50 por cento da força de trabalho em alguns hospitais.

Pode-se depreender, assim, que se por um lado o trabalho voluntário traz benefícios às organizações, por outro, pode trazer algumas dificuldades. Problemas como luta por espaço, desrespeito por regras e processos cotidianos dos hospitais e conflitos com os profissionais dos hospitais acarretam conflitos e dificuldades, às vezes, irreversíveis. Neste sentido a gestão do trabalho voluntário em organizações complexas não é tarefa simples, razão pela qual "seus gerenteslutam para equilibraressas diferenças comrecursos financeiros e organizacionaispara apoiarcontinuamente com osserviços voluntários" (MEYER JR., PASCUCCI e MURPHY, 2010, P. 4).

É neste cenário que estão inseridos os voluntários e seu trabalho em hospitais. Considerálos meros coadjuvantes seria um erro de parte dos gestores. Um dos principais desafios é a forma como os voluntários são selecionados e preparados para participar de diversas atividades dentro de uma organização complexa como o hospital.

Destaque-se a importância da compreensão, de parte da gestão, da identificação dos recursos considerados essenciais para a qualidade dos serviços da organização bem como de sua efetividade, na busca de uma associação positiva entre efetividade dos serviços e qualidade percebida (CRUZ, et al, 2013). O pressuposto aqui é que existe uma aparente relação entre a efetividade de gestão do trabalho voluntário e a qualidade dos serviços prestados em uma unidade hospitalar.

\section{METODOLOGIA}

A presente pesquisa caracteriza-se como um estudo de caso de natureza qualitativa. Segundo Creswell (2009) o estudo de caso caracteriza-se como um estudo aprofundado a respeito de determinado fenômeno. Este tipo de estudo permite explorar determinadas características da vida real das organizações, em suas atividades e práticas efetivas, destaca Remenyi et al (1998).

Os dados foram coletados, entre março de 2012 e junho de 2013. As principais fontes de dados foram: 1) entrevistas semi estruturadas com 4 (quatro) gestores e 5 (cinco)voluntários; 2) documentos e publicações da organização e 3) observação não participante.

Tabela 1: Perfil dos Respondentes

\begin{tabular}{lc}
\hline Tipo & Número \\
\hline Alta Gestão & 2 \\
Média Gestão & 1 \\
Gestão Operacional & 1 \\
Voluntários & 5 \\
Total & 9 \\
\hline
\end{tabular}

Fonte: Autores 

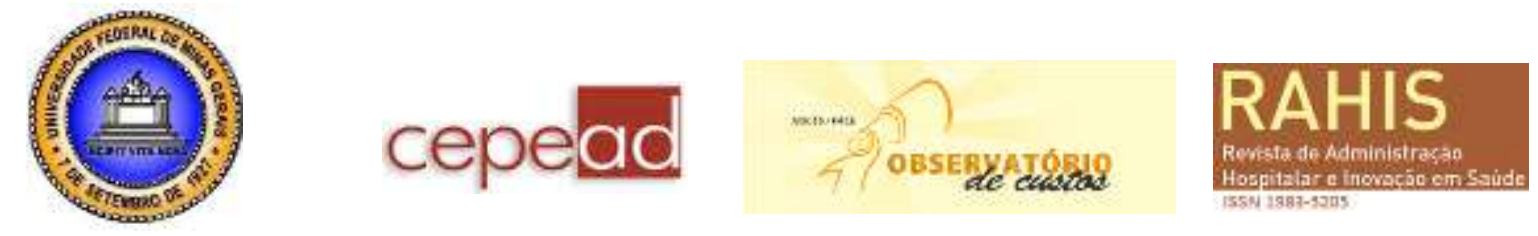

As entrevistas foram gravadase os pesquisadores realizaram anotações, como observadores não-participantes, registrando-as emdiários de campo. Os dados foram analisados por meio da técnica deanálise de conteúdo (Bardin, 1977).

Buscou-se, por meio da pesquisa, identificar os seguintes aspectos do trabalho voluntário: a. Posicionamento atual; b. Objetivos dos setores responsáveis pelo voluntariado no hospital; c. Gestão do Trabalho Voluntário; e. Posicionamento do voluntariado na estrutura da organização; f. Frentes de atuação do voluntariado no hospital e suas principais estratégias; g. Principais desafios enfrentados pelos gestores na realização do trabalho voluntário; h. Principais contribuições e benefícios do voluntariado no hospital, a partir do ponto de vista dos gestores e dos próprios voluntários; i. Dificuldades enfrentadas no desenvolvimento do voluntariado no hospital; j. Evolução da gestão do Trabalho Voluntário ao longo dos anos.

\section{Perfil do Hospital Foco do Estudo}

O hospital comunitário localiza-se em Curitiba, capital do estado do Paraná, sul do Brasil e tem como data de fundação o ano de 1958. A organização é de caráter comunitário, de natureza confessional, filantrópico e credenciado pelo Sistema Único de Saúde (SUS) como prestador de serviços de saúde, com $100 \%$ do seu atendimento voltado para a comunidade e tem por missão a excelência na prestação de serviços à comunidade e contínuo desenvolvimento do ensino e da pesquisa, tendo como um de seus compromissos a formação de recursos humanos altamente qualificados para o atendimento da saúde.

O Hospital conta com 207 leitos e nele atuam mais de 1500 profissionais.

Tabela 2: Atendimentos do Hospital em 2012

\begin{tabular}{ll}
\hline Tipo & Número \\
\hline Internamentos & 41.364 \\
Atendimentos no Pronto Socorro & 50.256 \\
Atendimentos no Pronto Atendimento & 45.408 \\
Atendimentos Ambulatoriais & 76.692 \\
Atendimentos no Centro Cirúrgico & 10.351 \\
Total & $\mathbf{2 2 4 . 0 7 1}$ \\
\hline
\end{tabular}

Fonte: Relatório de Indicadores Assistenciais do Hospital Comunitário - 2012

\section{ANÁLISE E DISCUSSÃO DOS DADOS}

\section{O TRABALHO VOLUNTÁRIO: CARACTERÍSTICAS E RELEVANCIA}

Do total de 224.071 atendimentos que o hospital comunitário realizou, em 2012, 27.003 atendimentos se deram por meio do programa de voluntariado do hospital comunitário (Documentos Internos do Hospital). Tal número de atendimentos aponta a relevância do trabalho voluntário realizado por 57 pessoas atuantes dos 82 voluntários que são distribuídos em várias frentes de trabalho.

A relevância do trabalho voluntário pode ser constatada com base em quatro dimensões, a saber: Humanização, Potencialização do Clima Interno, Contribuição Direta e Indireta de Recursos Internos, Contribuição na gestão do Hospital e do Programa de Voluntariado e Reforços da 

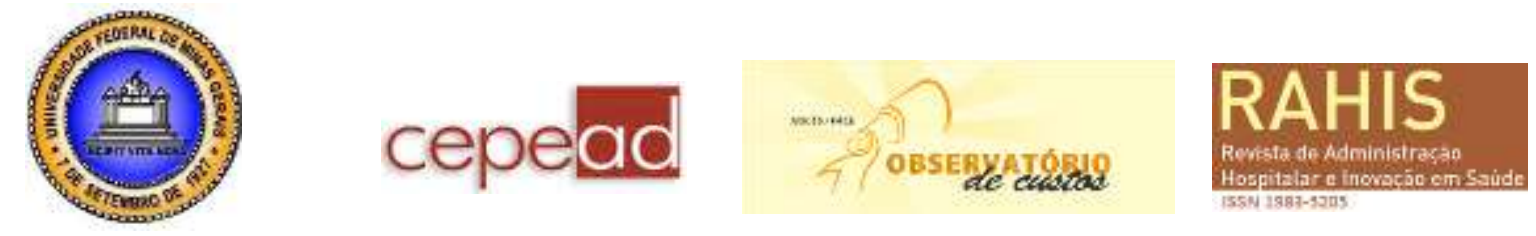

Legitimidade Social. Tais dimensões são evidenciadas tanto nas entrevistas realizadas com gestores dos diversos níveis hierárquicos, quanto na observação não participantes dos pesquisadores.

Quanto aos principais benefícios, todos os gestores e voluntários entrevistados, apontam, em primeiro lugar, ser o serviço realizado pelos voluntários um grande diferencial de humanidade. A gestora operacional afirma que os voluntários "estão liberados de serviços pontuais técnicos e passam a ser o filão da humanidade" (entrevista). Dois gestores, sendo um da alta e o outro da média gestão, e dois voluntários afirmam que o tratamento prestado, por este serviço, melhora o ambiente interno do hospital influenciando tanto os pacientes, quanto os próprios colaboradores. Um dos voluntários destacou que foi o tratamento humanizado que recebeu dos voluntários quando estava acompanhando um de seus familiares internado, neste hospital, que o tornou voluntário. $\mathrm{O}$ perfil humanizador manifestado no atendimento ao paciente tem agido como motivador para que se tornasse um voluntário da própria organização pesquisada. Isto é reforçado por Meyer Jr., Pascucci e Murphy (2010), quando destacam o papel do voluntariado em hospitais. Percebe-se aqui a preocupação recorrente, dos entrevistados, com a dimensão da humanização.

Pode-se observar que junto aos familiares, colaboradores e pacientes, os voluntários se mostram presentes, com atenção, cuidado e afeto. Nos momentos de vulnerabilidade, como destaca um gestor operacional: "eles estão sempre com um sorriso no rosto e um ar de acolhida". (entrevista). Para um dos membros da alta gestão, o voluntariado é fonte de humanidade e acrescenta, ainda, a importância do testemunho - coerência - de vida destacando que: "O serviço prestado por voluntários do hospital é de grande relevância, especialmente nas perspectivas da humanização da assistência e da transformação da sociedade pelo testemunho de solidariedade" (entrevista). Essas percepções indicam os benefícios da ação voluntária nas questões de humanização, tão cruciais em organizações hospitalares. Isto é reforçado pelo destaque dado por Hudson (1999, p. 11) e Anheier e Salamon (1999), ao se referirem a participação e posicionamento dos voluntários na vida pública e no exercício da cidadania. Tal posicionamento apresenta relevância, pois corrobora com a Política Nacional de Humanização brasileira que destaca como um de seus macro-objetivos "ampliar as ofertas da Política Nacional de Humanização aos gestores e aos conselhos de saúde, priorizando a atenção básica/fundamental e hospitalar, com ênfase nos hospitais de urgência e universitários" (Política Nacional de Humanização, Disponível em: <http://portal.saude.gov.br/portal/saude/cidadao/visualizar_texto.cfm?idtxt=28291> Acesso em: 15 de junho de 2013).

Em segundo lugar, destaca-se a influência dos voluntários no clima organizacional com entusiasmo e motivação como destacam diversos gestores entrevistados do escalão intermediário e da alta gestão. Assim, dois gestores, da média e alta gestão, apontaram que, em momentos de crise, os voluntários por estarem mais "livres" dos compromissos diários, constituem-se em fonte de otimismo e exemplo de perseverança e generosidade. Neste particular um dos gestores do nível intermediário assim se expressou: "Os voluntários influenciam positivamente o clima interno. Por vezes, 'seguram' os colaboradores. Permanecem motivados, mesmo nos momentos difíceis, e são exemplos de determinação" (entrevista). Corroborando com este entendimento o gestor operacional do serviço de voluntariado manifestou-se destacando que: "Após a implantação do Programa de Voluntariado o hospital tornou-se um Hospital mais feliz" (entrevista). Isto reforça o 

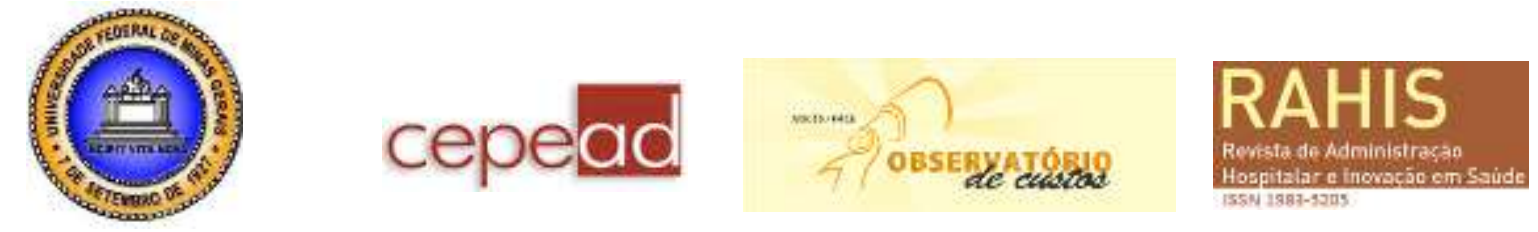

que destaca os estudos de Oster (1995) e Meyer Jr., Pascucci e Murphy (2010) ao se referirem ao trabalho voluntário como estratégico para a gestão das organizações sem fins lucrativos como os hospitais.

Ao abordar o cuidado com as pessoas um membro da alta gestão destacou que "o voluntário agiliza e otimiza a vida dos pacientes em todo o hospital" (entrevista). Reforçando a importância do trabalho voluntário o gestor operacional afirmou que "após serem capacitados cuidadosamente, os voluntários prestam serviços pontuais como levar os pacientes de seu leito até o centro cirúrgico ou sala de exames" (entrevista). Percebe-se assim que os voluntários acabam contribuindo na otimização das atividades dos profissionais de saúde. E como destacou o gestor do trabalho voluntário "o tempo que os técnicos de enfermagem poderiam estar perdendo tempo por acompanhar os pacientes, de um local a outro do hospital, eles realizam outros procedimentos mais técnicos que os voluntários não têm habilitação para realizar, tais como: banho, cuidados paliativos e medicamentosos" (entrevista). Pode perceber claramente que os voluntários, com seu trabalho, contribuem efetivamente, para que os profissionais da saúde tenham mais tempo para dar uma atenção mais acolhedora e atente às pessoas que estão privadas de suas plenas capacidades.

Em terceiro lugar destaca-se a questão financeira. Neste aspecto os gestores entrevistados foram unânimes em afirmar que a questão financeira traz benefícios diretos ou indiretos ao hospital. Muitos voluntários acabam por conseguir alguns recursos como dinheiro em espécie ou materiais de trabalho no hospital, tais como: macas e cadeira de rodas, para a realização das atividades diárias. Como benefício indireto, como afirma o gestor da alta gestão: “(...) a atuação dos voluntários na área dos hospitais públicos tem relevância, pois facilita a assistência hospitalar. É conhecido o processo de sucateamento da saúde pública no Brasil, em razão do subfinanciamento praticado". Como destacou o gestor somente tem sido possível alcançar certo equilíbrio financeiro graças ao trabalho realizado por voluntários em certas áreas de atividade que envolve serviços assistenciais. Isto reforça os resultados dos estudos desenvolvidos por Meyer Jr., Pascucci and Murphy, (2012) e Handy et al ao destacarem que os voluntários ajudam a reduzir os custos operacionais quando realizam, de outra forma, o trabalho de colaboradores os quais implicariam em remuneração e custos operacionais.

As percepções dos gestores e de dois voluntários apontam que os voluntários disseminam, à comunidade externa, aspectos referentes ao bom ambiente interno do hospital. Isto indica que há o reforço do ambiente humanizador interno da organização de saúde, bem como há contribuição com a formação da opinião pública referente a sua legitimidade social na prestação dos serviços em saúde pública. "Uma boa reputaçãoserve comoum tapete vermelhoquandose trata de atrairpacientes, recursos eparcerias" (PASCUCCI, MEYER JR. and MURPHY, 2010, P. 09).

Em quarto lugar é possível destacar a contribuição do voluntariado na gestão do próprio hospital e do programa de voluntariado. Pode-se perceber que o programa de voluntariado é discutido sistematicamente em reuniões, tanto em âmbito nacional quanto internacional, segundo dois gestores da alta gestão. O Grupo Educacional, no qual o Hospital Comunitário pertence, desenvolveu e implementa a Política Institucional de Humanização para a Área da Saúde. Nesta política estão descritas a conceituação, objetivo, diretrizes, dispositivos e parâmetro para toda a área de saúde (Política Institucional de Humanização do Grupo Marista). Para tanto, "o 

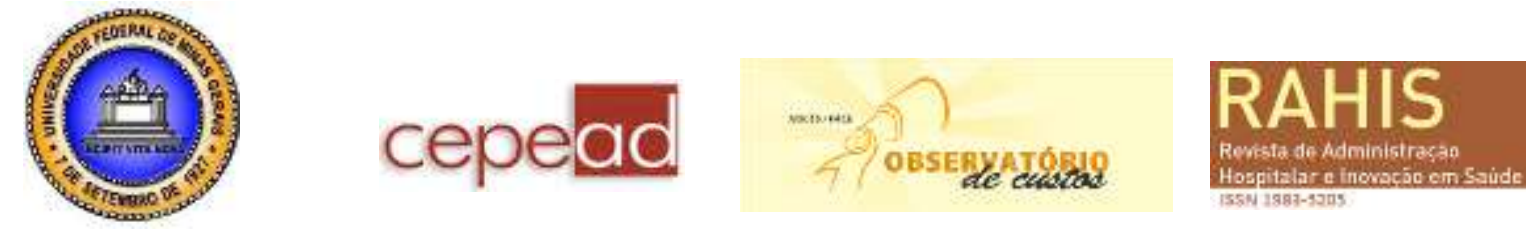

planejamento estratégico do hospital tem de constar estas políticas para direcionar as suas ações estratégicas" (entrevista), afirma um gestor da alta gestão.

Outras situações que sugerem a contribuição do voluntariado nos processos de gestão são evidenciadas nas entrevistas. Assim, ao comentar sobre a relação entre voluntários e colaboradores, um dos voluntários entrevistados enfatizou que "Alguns colaboradores tem receio de que nós voluntários iremos roubar o seu emprego e não estamos aqui para isso" (entrevista). Neste sentido, "a gestão do hospital junto à coordenação do voluntariado desenvolve algumas ações estratégicas de sensibilização dos colaboradores referente ao papel dos voluntários no ambiente hospitalar, bem como estabeleceram uma política de não contratação de voluntários nas equipes de colaboradores, para não reforçar e potencializar quaisquer problemas referente a esta questão" (entrevista), afirma a gestora operacional. "É critério de seleção e recrutamento de voluntários não aceitar àqueles que têm a pretensão de um dia ser colaborador da organização" (entrevista), afirma a gestora.

Na gestão do voluntariado observa-se que há o estabelecimento de estratégias com relação ao acompanhamento dos voluntários e colaboradores no dia a dia hospitalar. Todos os casos são acompanhados e visam ter ações imediatas para contribuir neste processo de gerir problemas, crises, trabalho dos voluntários e dos colaboradores. Há também a realização de escuta dos anseios, dificuldades e sugestões por parte dos voluntários. Afirma o gestor da média gestão: "Os relatos são compilados pela gestão do voluntariado e levados em reuniões formais ou informais à equipe gestora do hospital" (entrevista). Identifica-se que há envolvimento e acompanhamento entre a equipe gestora do hospital com a equipe gestora do voluntariado de maneira sistematizada e contínua.

Um dos voluntários, referindo-se a suas ações estratégicas, deixou claro que: “(...) várias vezes, os voluntários contribuíram para questões de melhorias dos próprios processos do hospital" (entrevista). Como exemplo, lembra que um voluntário percebeu e apontou à gerente de enfermagem sobre a vulnerabilidade de segurança que o hospital tinha em relação ao acesso do público externo a quaisquer alas do hospital. Ele aponta: "Prontamente a direção do hospital, reuniu-se com as partes interessadas de sua equipe gestora e, imediatamente, tomaram as providencias relacionadas a essa situação" (entrevista).

Em quinto lugar destaca-se a ideia de que há, por meio dos voluntários, uma maior aproximação da sociedade em relação ao hospital. Por meio dos voluntários, "a sociedade se faz de alguma forma mais presente" destacou um membro da alta gestão (entrevista). Pode-se perceber que os voluntários trazem os anseios e a realidade do ambiente hospitalar para a comunidade, constituindo-se em grandes intermediários entre o hospital e a sociedade. Neste sentido, uma voluntária chegou a afirmar que já teve de convencer várias pessoas, até mesmo familiares, que mesmo que o hospital seja mantido por uma mantenedora, que tenha boas condições financeiras, os pacientes são carentes e necessitam de seu voluntariado. Além do mais, está convencida que a instituição toda não visa fins lucrativos e por isso escolheu trabalhar de voluntária neste hospital.

Estudos (Moore, 2000; Dart, 2004), apontam que a legitimidade social favorece as instituições sem fins lucrativos a construir uma boa imagem e um ambiente de autorização de seu funcionamento. Isso vem favorecer vários aspectos, dentre eles a captação de recursos dada à imagem positiva a que conseguiu consolidar na sociedade civil. 

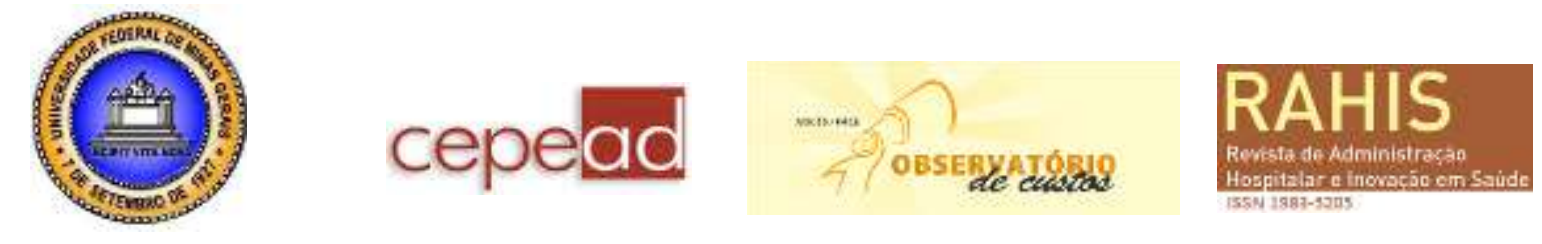

\section{Desafios da Gestão do Trabalho Voluntário}

Como principais dificuldades e desafios para a gestão do trabalho podem ser destacados dois principais fatores: a escassez de recursos e necessidade de maior profissionalização da gestão do voluntariado.

Tanto o gestor operacional como todos os voluntários entrevistados foram unânimes em apontar a escassez de recursos materiais básicos como a maior dificuldade. Um dos voluntários afirma: "É inadmissível a falta de cadeira de rodas num hospital" (entrevista). Dois voluntários salientaram que a falta de consciência dos parentes dos pacientes internados, relacionado ao bem público, chega a ser surpreendente, pois relataram que, várias vezes, cadeiras de rodas foram levadas pelas famílias e descartadas em locais públicos da cidade ou até mesmo foram furtadas do hospital.

Os gestores da alta, média e gestão operacional e dois dos voluntários pesquisados apontam sobre a preocupação da escassez de humanização nos profissionais de saúde. O comportamento dos profissionais da saúde que é "frio e muito técnico, chegando a ser "seco"" (entrevista), afirma um gestor da alta gestão.

A esta questão, faz-se importante apontar que o hospital pesquisado investe muito nos processos de humanização de processos e pessoas. Foi possível perceber esta questão tanto nas observações não participantes quanto em documentos internos do hospital pesquisado."O hospital é gerido por meio da gestão participativa que é entendida como processo de coordenação, articulação e interação de recursos e trabalho humano que incluem os diferentes sujeitos que os compõem. Para que a gestão participativa ocorra, foram criados: 1 . espaços e diálogos; 2 . Fóruns permanentes em gestão participativa compostos por colaboradores e membros da sociedade civil, sendo eles: usuários/clientes e voluntários; 3. formação continuada de gestores para a articulação de processos em gestão participativa; 4. estruturação e desenvolvimento de reuniões periódicas em gestão participativa, com colaboradores de diferentes níveis hierárquicos; 5. reestruturação das ouvidorias; 6. canais de diálogo entre os setores da área de saúde com o objetivo de registrar elogios, sugestões e não conformidades" (POLÍTICA INSTITUCIONAL DE HUMANIZAÇÃO DO GRUPO MARISTA, 2012, P. 39).

A implantação da Política Institucional de Humanização que teve como objetivo orientar um processo de humanização sistemático e orgânico em consonância com a Política Nacional de Humanização e os Valores Institucionais constituiu-se em marco importante para que o hospital Comunitário melhora-se o processo de humanização em todas as áreas. Esta nova política teve como foco traçar 10 diretrizes principais, a saber: Acolhimento, ambiência, Clínica Ampliada, Comunicação em Saúde, Cuidados Paliativos, Espiritualidade, Formação de Profissionais de Saúde, Gestão Participativa, Tanatologia e Valorização e Cuidado com profissionais de saúde. Estas diretrizes corroboraram para a potencialização das finalidades do Programa de Voluntariado, bem como no desenvolvimento do próprio hospital.

Ao serem indagados sobre os principais desafios sobre o trabalho voluntário, três gestores foram uníssonos ao afirmarem que estão relacionados às questões de profissionalização da gestão. Aspectos como a atração, retenção, qualificação, acompanhamento personalizado, avaliação dos 

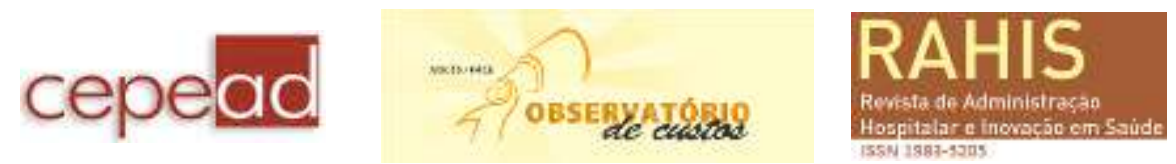

voluntários e dos projetos e continuidade do trabalho dos voluntários, foram recorrentes nas entrevistas realizadas com os voluntários.

No que se refere ao processo de atração, um dos gestores da alta hierarquia do hospital destacou que "o perfil dos voluntários tem de transcender àqueles que estão aposentados" (entrevista). O referido gestor ainda destaca que há a necessidade de repensar as atividades e os propósitos dos projetos de voluntariado existentes e, a partir daí, estabelecer novos processos de atração de voluntários.

Quanto à qualificação dos voluntários, um gestor da alta gestão afirma uma meta a ser perseguida: "Ampliar a mentalidade do voluntário para que o trabalho, por ele realizado, não seja apenas "anestesia" para suas necessidades pessoais, e sim contribuição para emancipação dos sujeitos por ele atendidos. Outro aspecto que merece ser trabalhado com os voluntários é o desenvolvimento de suas habilidades educativas frente aos pacientes, sendo hoje apenas trabalhadores braçais, creio que no futuro poderemos ter voluntários com capacidade de fornecer educação em saúde." (entrevista).

Dois gestores da alta e média gestão apontam a necessidade de criar padrões de avaliação qualitativos e quantitativos para as atividades desenvolvidas pelo Programa de Voluntariado e, além disso, para que desenvolvam atividades que transcendam a questões operacionais, ou seja, mais estratégicas.

Ainda, como principais desafios, um gestor da alta gestão, aponta a sustentabilidade econômica financeira. Tal afirmação evidencia a constatação de que "Hospitais sem fins lucrativos, portanto, sofremem perseguir suas missões dignas para servir os pacientes carentes que não podem pagar, tendo insuficiente financiamento público. Como resultado hospitais lutam para prosseguir a missão social enquanto equilibram o orçamento. A sua sustentabilidade está em risco". (PASCUCCI, MEYER JR. AND MURPHY, 2010, P. 03).

Tabela 3: Trabalho Voluntário e suas Características

\begin{tabular}{|c|c|}
\hline & Relevância do Trabalho Voluntário \\
\hline Humanização & \\
\hline Potencialização do Clima Interno & \\
\hline Contribuição de Recursos Internos & \\
\hline Contribuição na Gestão do Hospital & do Programa de Voluntariado \\
\hline Reforços da Legitimidade Social & \\
\hline & stão do Trabalho Voluntário e Desafios \\
\hline Escassez de Recursos & Materiais \\
\hline & Humanos Qualificados \\
\hline Profissionalização dos Processos de & Atração \\
\hline Gestão & Retenção \\
\hline & Desenvolvimento - acompanhamento e avaliação \\
\hline & Avaliação do Programa e dos Projetos \\
\hline & Sustentabilidade Econômico-financeira \\
\hline
\end{tabular}

Fonte: Autores - coleta de dados

\section{Discussão}

É possível destacar a significativa contribuição do trabalho voluntário para o público interno do hospital, bem como para a comunidade na qual a organização está inserida. A humanização é identificada como a maior prestadora de benefícios, pois qualifica o processo de 

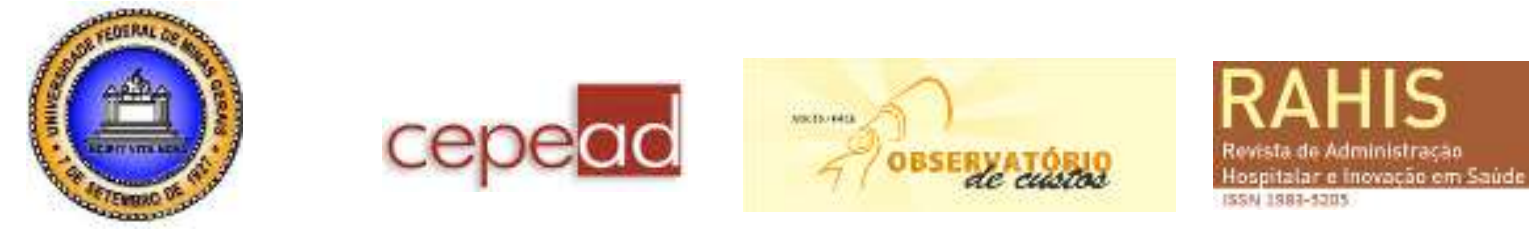

atendimento aos pacientes além de contribuir para a integração de setores voltados para o atendimento ao paciente. Da mesma forma fortalece o clima interno e reforça as políticas da organização em especial aquelas voltadas para viabilizar a Política Nacional de Humanização. Outros aspectos evidenciados na pesquisa reforçam a relevância do trabalho voluntario em organização hospitalares como apontado por Meyer Jr. et al (2012) e Moore (2000) os quais transcendem os cuidados direto aos pacientes. A contribuição com a economia de recursos, gestão hospitalar e legitimidade social são pontos de destaque da pesquisa.

Os entrevistados foram uníssonos em apontar melhoria na gestão do voluntariado no decorrer dos últimos cinco anos. Observou-se que os padrões de seleção de voluntários, a fidelização e o compromisso dos voluntários cresceu nos últimos três anos, constituindo-se em benefícios gerados com base na gestão do trabalho voluntário no hospital.

Embora a gestão do trabalho voluntário venha se aprimorando nos últimos anos, como apontaram as entrevistas e a observação não participante, a escassez de recursos e a profissionalização dos processos de voluntariado são questões relevantes para o aprimoramento da gestão do voluntariado no Hospital Comunitário. Há a necessidade de melhorar tanto o foco de atratividade dos voluntários, quanto o de repensar estrategicamente no papel das atividades e programas disponibilizados aos voluntários. Verifica-se a necessidade de aprimoramento das formações e desenvolvimento propostos aos voluntários, bem como o desenvolvimento de uma cultura de acompanhamento e feedback por parte da gestão do voluntariado. Como destacam Meyer Jr., Pascucci and Murphy (2012), quanto melhor gerido for o trabalho voluntário, melhores serão os serviços hospitalares e, consequentemente, mais se objetivará o cumprimento da missão a que se propõe a organização. Evidencia-se, nesta questão, a clarificação dos propósitos da ONG pesquisada que é atender a uma missão social, como destacam alguns autores (Oster, 1995; Drucker, 1997; Hudson, 1999; Moore, 2000; Dart, 2004).

A experiência acumulada com a gestão de colaboradores não remunerados, como é o caso dos voluntários, perpassa os requisitos típicos da gestão de pessoas em organizações, bom relacionamento interpessoal, como destaca o gestor operacional e todos os voluntários entrevistados. "A gestão de voluntários é distinta da gestão de colaboradores pois são inúmeras as diferenças entre os dois grupos" destacou um dos gestores (entrevista). Aspectos como motivação, relações de trabalho, naturezas de trabalho bem como expectativas são distintas e requerem sensibilidade à gestão. Neste aspecto destacou um dos gestores do setor entrevistados: "A sensibilidade e o olhar atento da gestão estão presentes tanto na informalidade, durante o cafezinho, quanto nos momentos formais, como nas reuniões formais e no tratamento dado ao feedback relacionado às atividades desenvolvidas e outras a serem desenvolvidas pelos voluntários no hospitals" (entrevista). Aspectos como estes reforçam o que já destacava Oster (1995) ao ressaltar a importância da gestão de recursos humanos nas ONGS, em especial a tarefa de combinar motivação e controle com pessoas que não são remuneradas como os voluntários.

\section{CONSIDERAÇÕES FINAIS}

O estudo revelou que a organização hospitalar não pode prescindir dos serviços prestados pelo trabalho voluntário. Foram cinco as principais contribuições do trabalho voluntário 

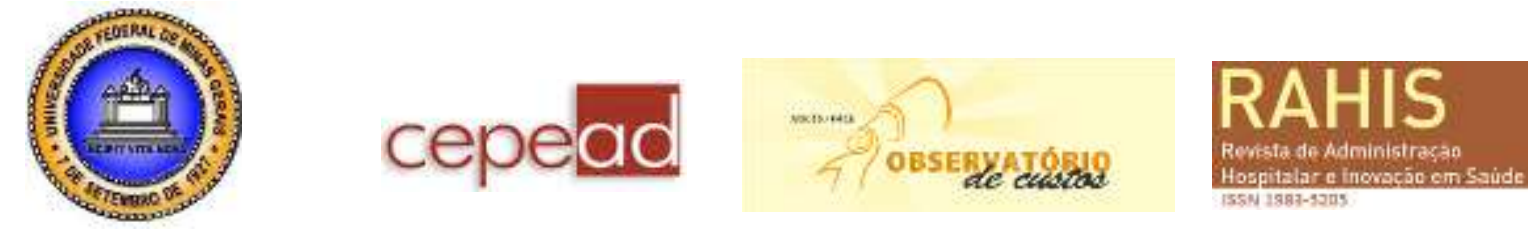

identificadas: humanização, fortalecimento da cultura, contribuição direta e indireta de recursos internos, a contribuição do voluntariado na gestão do próprio hospital e do programa de voluntariado e os reforços de legitimidade social.

Quanto a desafios enfrentados pela gestão do trabalho voluntário foram identificados tanto aspectos relacionados à escassez de recursos, quanto à falta de profissionalização da gestão dos processos de voluntariado, tais como: atração, retenção, desenvolvimento e avaliação. Observouse um sensível avanço na gestão do trabalho voluntário, principalmente nas práticas deste grupo de colaboradores que resultaram em um verdadeiro aprendizado organizacional. Certamente progressos contínuos são necessários e esperados neste setor no futuro.

Identificou-se também uma reduzida participação dos voluntários em atividades do hospital. Observou-se a necessidade de uma maior profissionalização na gestão do trabalho voluntário como forma de se melhor gerenciar este valioso trabalho e de ampliar sua participação em outras áreas do hospital envolvendo serviços de apoio aos pacientes, atividades auxiliares em campanhas de captação de fundos ou de promoção da imagem do hospital junto a comunidade.

Contudo, esta profissionalização constitui-se em um processo lento que requer mudanças graduais de procedimentos e cultura em uma organização conhecida por sua complexidade e diversidade de interesses. Além deste aspecto, a qualificação da gestão de voluntários irá melhor qualificar o valor agregado pelo próprio trabalho voluntário.

Dada a relevância do voluntário para a organização hospitalar e para o cumprimento da missão social do hospital comunitário melhorias na gestão do trabalho voluntário, certamente, irão impactar positivamente a qualidade dos serviços prestados e o desempenho organizacional.

A fim de avançar e aprofundar as pesquisas na área da gestão do voluntariado em ONGS sugere-se o desenvolvimento de estudos que, por meio de trabalhos mais aprofundados e com base em um conjunto de casos, examinem o impacto do trabalho voluntário na gestão hospitalar e na qualidade dos serviços prestados. Uma segunda temática para futuros estudos está relacionada ao exame de políticas e práticas estratégicas de implantação e desenvolvimento de políticas de humanização em organizações hospitalares.

\section{REFERÊNCIAS}

ANHEIER, H. K. and SALAMON, L.M. Volunteering in cross-national perspective: Initial comparisons. Law and Contemporary Problems, 1999. 62(4), 43-66.

Bardin, L. L`analyse du contenu. Paris: Quadrige, Presses Universitaries de France, 1977.

BRYSON, J. M. Strategic planning for public and nonprofit organizations. San Francisco: JossyBass, 2004. (ca. 3 e 7).

CRESWELL L. J. W. Research design: qualitative, quantitative, and mixed methods approaches. Thousand Oaks: Sage Publications, 2009.

CRUZ, J. A. W.; QUANDT, C. O.; MARTINS, T. S.; KATO, H. T.; MARTINS, R. R. R. How Does The Structure Of Social Networks Affect The Performance Of Its Actors? - A case study in 

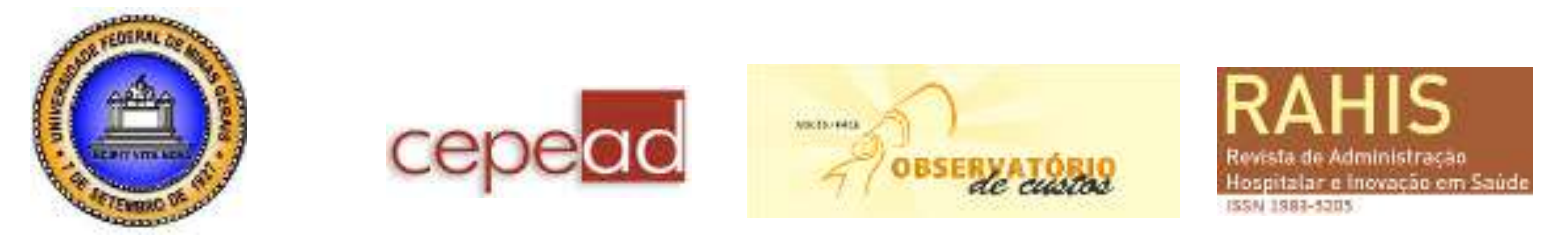

the Brazilian context. Academy of Management, 2013.

DART, R. The Legitimacy of Social Enterprise. Nonprofit Management \& Leadership. vol. 14, n.4, 2004, 411-424.

DOMENEGHETTI, Ana Maria Martins de Souza. Voluntariado: Gestão do trabalho voluntário em organizações sem fins lucrativos. São Paulo Editora Esfera, 2001.

DRUCKER, Peter F. Administração de Organizações Sem Fins Lucrativos: Princípios e práticas. 4. Ed. São Paulo: Livraria Pioneira Editora, 1997.

DRUCKER, P. F. (2005). Managing the nonprofit organization: Principles and Practices. New York: Harper Collins.

GRUPO MARISTA. Disponível em: <http://www.grupomarista.org.br> Acessado em 15 de junho de 2013.

HOSPITAL UNIVERSITÁRIO CAJURU. Disponível em:

<http://www.pucpr.br/saude/alianca/cajuru/> Acessado em 11 de junho de 2013.

HUDSON, Mike. Administrando Organizações do Terceiro Setor. São Paulo. Makron Books, 1999.

KISNERMAN, N. Introdução ao trabalho social. São Paulo. Editora Moraes, 1983.

KOHAN, Felisa F. Entrenamiento para voluntarias en servicio social. Buenos Aires:1965.

MEYER JR.V.; PASCUCCI, L. e MANGOLIN, L. Gestão estratégica: um exame de práticas em universidades privadas. Rev. Adm. Pública vol.46 n.1 Rio de Janeiro Jan./Feb. 2012.

MEYER JR. V.; PASCUCCI, L; MURPHY, J.P. Hospital Volunteers: Good Citizens or Strategic Agents? ENANPAD, 2010, Rio de Janeiro.

MEYER, V., PASCUCCI, L., \& MURPHY, J. P. (2012). Volunteers in Brazilian Hospitals: Good Citizens or Strategic Agents?. Voluntas: International Journal of Voluntary and Nonprofit Organizations, 29(1), 1-18

MINTZBERG, Henry. The fall and rise of strategic planning. Harvard business review, v. 72, n. 1, p. 107-114, 1994.

MOORE, M. Managing for Value: Organizational Strategy in For-Profit, and Governamental Organizations. Nonprofit and Voluntary Sector Quaterly, 29, 2000, 83-204. 

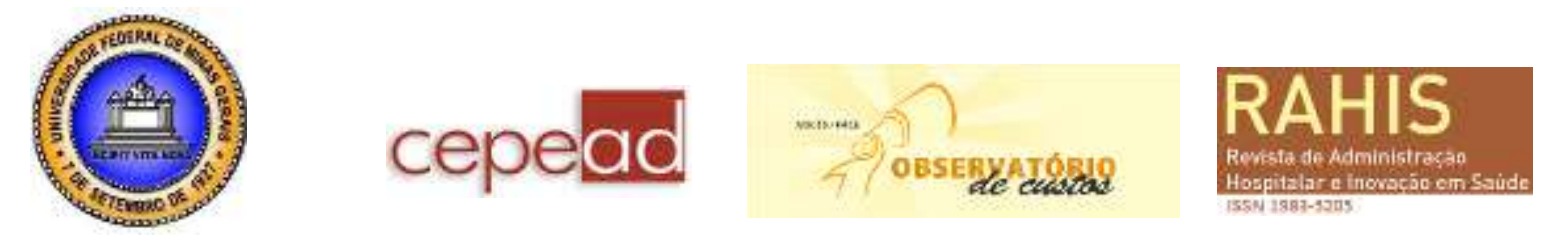

MORIN, E. A Religação dos Saberes: o desafio do século XXI. SP. Bertrand Brasil, 2004.

ONU. Programa de Voluntários. Disponível em <http://www.unv.org/how-to-volunteer> Acesso em 20 de abril de 2012.

OSTER, S. Strategic Management for Nonprofit Organizations. New Yourk: Oxford University Press, 1995. Cap. 4, 5 e 6.

PASCUCCI, L.; MEYER JR. V. Formação de Estratégias em Sistemas Complexos: Estudo Comparativo de Organizações Hospitalares sob a Perspectiva Prática. ENANPAD, 2011, Rio de Janeiro.

PASCUCCI, L.; MEYER JR.V. e MURPHY, J.P. Strategic Practices in Nonprofit Hospitals: The Convergence of Social Mission and Sustainability.ENANPAD, 2010, Rio de Janeiro.

POLÍTICA NACIONAL DE HUMANIZAÇÃO. Disponível em: $<$ http://portal.saude.gov.br/portal/saude/cidadao/visualizar_texto.cfm?idtxt=28291> Acessado em 15 de junho de 2013.

POLÍTICA INSTITUCIONAL DE HUMANIZAÇÃO DO GRUPO MARISTA / Área da Saúde. Curitiba: Associação Paranaense de Cultura, 2012.

SOARES, A.C.A. A \& MELO, M.C. Gestão do Terceiro Setor: Uma Prática Social?Revista de Gestão da USP, v. 17, 1, p. 1-11, 2009.

STACEY, R. D. Complexity and creativity in organizations. Berrett-Koehler Publishers, 1996.

RIDDER, H-G.; PIENING, E. P.; BALUCH, A. McC. The Third Way Reconfigured: How and Why Nonprofit Organizations are Shifting Their Human Resource Management. Voluntas: International Journal of Voluntary and Nonprofit Organizations. 2012. 23:605-635.

REMENYI, D. et al. Doing research in business and management. London: Sage Publications, 1998.

STACEY, R. Strategic Management and Organizational Dynamics. Third Edition, Pearson Education Ltd, Essex, 2000. 